Claremont Colleges

Scholarship@ Claremont

All HMC Faculty Publications and Research

HMC Faculty Scholarship

9-1-2004

\title{
Immunogold Labeling to Enhance Contrast in Optical Coherence Microscopy of Tissue Engineered Corneal Constructs
}

Chris B. Raub

Elizabeth J. Orwin

Harvey Mudd College

Richard C. Haskell

Harvey Mudd College

\section{Recommended Citation}

Raub, C.B., E.J. Orwin, and R.C. Haskell. "Immunogold labeling to enhance contrast in optical coherence microscopy of tissue engineered corneal constructs." Proceedings of the 26th Annual International Conference of the IEEE, Engineering In Medicine and Biology Society, Vol. 1 (2004): 1210-1213.

This Conference Proceeding is brought to you for free and open access by the HMC Faculty Scholarship at Scholarship @ Claremont. It has been accepted for inclusion in All HMC Faculty Publications and Research by an authorized administrator of Scholarship @ Claremont. For more information, please contact scholarship@cuc.claremont.edu. 


\title{
Immunogold Labeling to Enhance Contrast in Optical Coherence Microscopy of Tissue Engineered Corneal Constructs
}

\author{
C. B. Raub ${ }^{1}$, E. J. Orwin ${ }^{2}$, R. Haskell ${ }^{3}$ \\ ${ }^{1}$ Department of Biology, Harvey Mudd College, Claremont, CA, USA \\ ${ }^{2}$ Department of Engineering, Harvey Mudd College, Claremont, CA, USA \\ ${ }^{3}$ Department of Physics, Mudd College, Claremont, CA, USA
}

\begin{abstract}
Our lab has used an optical coherence microscope (OCM) to assess both the structure of tissueengineered corneal constructs and their transparency. Currently, we are not able to resolve cells versus collagen matrix material in the images produced. We would like to distinguish cells in order to determine if they are viable while growing in culture and also if they are significantly contributing to the light scattering in the tissue. In order to do this, we are currently investigating the use of immunogold labeling. Gold nanoparticles are high scatterers and can create contrast in images. We have conjugated gold nanoparticles to antibodies specific to the $\alpha_{5} \beta_{1}$ integrins expressed in some corneal cells. This choice of target should allow assessment of the phenotypic behavior of the cells in the tissue, as different integrins are expressed in different phenotypes. This study applies the immunogold technique to study cultured corneal cells using the OCM with the ultimate goal of monitoring cellular behavior in engineered tissue and corroborating results from standard histological methods.
\end{abstract}

Keywords-Cornea, tissue engineering, optical coherence microscopy

\section{INTRODUCTION}

Recently, it has been discovered that there is a cellular contribution to corneal transparency, making observation of our tissues on the molecular level essential. In response, the characterization of the phenotype of corneal keratocytes in normal and wounded corneas has been the subject of much investigation. Stromal wounding in response to damage or surgical procedures initiates a distinct response in corneal keratocytes [1]. Keratocytes in the wounded region are activated to become repair fibroblasts, which proliferate and synthesize both extracellular matrix (ECM) components and enzymes to degrade ECM. The repair fibroblasts then differentiate further into either myofibroblasts or scar keratocytes. Myofibroblasts, which express $\alpha$-smooth muscle actin, act to contract the wound [2]. The transition from repair fibroblast to myofibroblast is reversible upon completion of the healing process. In contrast, if a repair fibroblast differentiates into a scar keratocyte, the process is irreversible and results in the formation of a corneal scar.

The three phenotypically distinct cell types are characterized by certain features. $30 \%$ by mass of the water soluble protein in quiescent rabbit keratocytes is comprised of the "corneal crystallins" transketolase (TKT) and aldehyde dehydrogenase 1 (ALDH1) [3]. In addition, it has been discovered that there is at least a $50 \%$ reduction in expression levels of these proteins when corneal haze following injury is present. At this time, cells have been activated to the repair or myofibroblast phenotype. It is hypothesized from these results that these two proteins act similarly to crystallin proteins in the lens of the eye - that is, they aggregate in the cell cytoplasm and contribute to index matching of the cytosol with the surrounding extracellular environment. As further evidence for this theory, Jester and colleagues have shown that light scatter from normal keratocytes in a transparent cornea comes entirely from the nucleus of the cell - the cell body does not scatter light [3].

Corneal stromal cells differentially express integrin receptors. Specifically, myofibroblasts express the $\alpha_{5} \beta_{1}$ integrin at higher levels than do repair fibroblasts, whereas quiescent keratocytes do not express the $\alpha_{5} \beta_{1}$ integrin $[4,5]$. Therefore, the $\alpha_{5} \beta_{1}$ integrin is a good marker for nontransparent corneal stromal cell phenotypes.

Immunogold labeling methods in electron microscopy are well established [6,7]. Immunogold labeling has recently been used in conjunction with reflectance confocal imaging to enhance contrast of cancer cells both in cervical tissue sections and in epithelial tissue constructs [8]. These studies suggest that gold labeling in general, and immunogold labeling in particular, might have application in studies of engineered tissue using optical coherence microscopy.

\section{Methodology}

\section{A. Gold Nanoparticle Formation}

Gold nanoparticles were made using the citrate reduction of $\mathrm{Au}$ (III) [9]. The amount of citrate was varied to produce $16 \mathrm{~nm}, 71.5 \mathrm{~nm}$, and $147 \mathrm{~nm}$ diameter gold nanoparticles. Upon complete formation of the particles, the $16 \mathrm{~nm}$ and $71.5 \mathrm{~nm}$ gold colloids were orange-red and deep red, respectively, whereas the $147 \mathrm{~nm}$ particles appeared as a purple precipitate. Further boiling of the particle solutions did not produce additional color change.

A test of particle monodispersity is to add PBS to a solution of gold particles. In the presence of $>7 \mathrm{mM}$ electrolytes, gold particles form aggregates, which appear as a purple precipitate [6,7]. $2 \mathrm{ml}$ each of PBS and the $16 \mathrm{~nm}$ and $71.5 \mathrm{~nm}$ gold colloids were combined, producing a purple precipitate. Gold nanoparticles in the presence of 10 mM HEPES buffer $\mathrm{pH} 7.4$ did not form precipitates when exposed to PBS.

\section{B. Gold Particle Imaging}

Naked colloidal gold particles were imaged with phase contrast microscopy and OCM. Phase contrast microscopy, 
with a 100x objective, revealed aggregates $1-10 \mu \mathrm{m}$ in diameter in the $147 \mathrm{~nm}$ diameter gold particle solution, and much smaller, more abundant particles in the $71.5 \mathrm{~nm}$ gold particle solution. These particles were monodisperse or in small clusters. No particles were detected in the $16 \mathrm{~nm}$ diameter gold particle solution using phase contrast microscopy.

OCM images were taken with a gain of 1000 using an $850 \mathrm{~nm}$ SLD light source. The resolution of the instrument is $5 \mu \mathrm{m}$ laterally and $10 \mu \mathrm{m}$ vertically.

\section{Immunogold Conjugation and Labeling of Cells}

$16 \mathrm{~nm}$ and $71.5 \mathrm{~nm}$ gold particles were conjugated to antibodies, and human corneal myofibroblasts were immunogold labeled using a procedure modified from Sokolov et. al. [8]. $71.5 \mathrm{~nm}$ gold was incubated with goat anti-mouse $\operatorname{IgG}\left(\mathrm{F}(\mathrm{ab})_{2}\right.$ antibody (Sigma) for 24 hours at 4 ${ }^{\circ} \mathrm{C}$, cells were trypsinized instead of being treated with collagenase, and cells were incubated in PBS/10\%FBS containing $0.02 \mu \mathrm{g} / \mu \mathrm{l}$ mouse anti- $\alpha_{5} \beta_{1}$ non-blocking antibody (Sigma), pelleted, and washed before incubation with immunogold conjugates for 6 hours at $4{ }^{\circ} \mathrm{C}$. Spectrophotometry was used to confirm conjugation of gold particles to antibody. Indirect immunofluorescence using the same antibodies as above (but with a FITC-conjugated secondary antibody fragment) confirmed the presence of $\alpha_{5} \beta_{1}$ on corneal myofibroblasts and confirmed antibody specificity.

Corneal myofibroblasts, grown on glass coverslips and fixed in methanol for 20 minutes at room temperature, were labeled with naked $16 \mathrm{~nm}$ and $71.5 \mathrm{~nm}$ gold by incubating the cells with the gold colloids diluted once in $20 \mathrm{mM}$ HEPES buffer, pH 7.4.

\section{Immunogold Labeling of Tissue-engineered Collagen Sponges}

Freeze-dried bovine type I collagen sponges were prepared according to previous methods [10]. Sponges were labeled either with naked $71.5 \mathrm{~nm}$ gold or were seeded with human corneal myofibroblasts at 400,000 cells $/ \mathrm{cm}^{3}$ and then allowed to incubate in Dulbecco's Modified Eagle's Medium at $37^{\circ} \mathrm{C}$ for 24 hours. They were then washed in PBS and incubated with the anti- $\alpha_{5} \beta_{1}$ primary and $71.5 \mathrm{~nm}$ gold-conjugated secondary antibodies previously mentioned. Antibody incubation occurred as previously mentioned, except that tissues were incubated with primary antibody for 12 hours at $4{ }^{\circ} \mathrm{C}$ and with $71.5 \mathrm{~nm}$ gold-conjugated secondary antibodies for 9 hours at $4{ }^{\circ} \mathrm{C}$.

\section{RESULTS \\ A. OCM Images of Gold Particles in Solution}

Differences were observed in the amount of backscattering coming from dilute aqueous solutions of the gold particles (Fig. 1). Larger particles scattered more intensely. Sedimentation of particle aggregates was detected in the $147 \mathrm{~nm}$ particle solution.
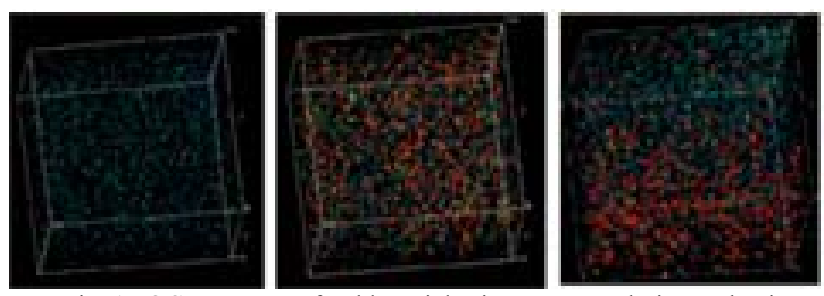

Fig. 1. OCM Images of gold particles in aqueous solution. Blue is relatively low backscattering; red is relatively high backscattering. $16 \mathrm{~nm}$ diameter gold nanoparticles (left panel) scatter less intensely than $71.5 \mathrm{~nm}$ diameter gold nanoparticles (central panel), which scatter less intensely than $1-10 \mu \mathrm{m}$ diameter gold aggregates of $147 \mathrm{~nm}$ gold particles (right panel). Images are $500 \mu \mathrm{m} \times 500 \mu \mathrm{m} \times 500 \mu \mathrm{m}$.

\section{B. Labeling of Collagen Sponge with Naked Gold Particles}

Naked $71.5 \mathrm{~nm}$ diameter gold nanoparticles adhered to a tissue-engineered collagen matrix (Fig. 2). Images of the same matrix location over the course of 3 hours show 71.5 $\mathrm{nm}$ diameter gold nanoparticles settling on the upper half of the matrix (Fig. 2, central panels). Extensive washing removed only a fraction of the nanoparticles (Fig. 2, bottom panel). After washing, backscattered intensity of the matrix was greater at all depths than that of the pre-incubation sponge.

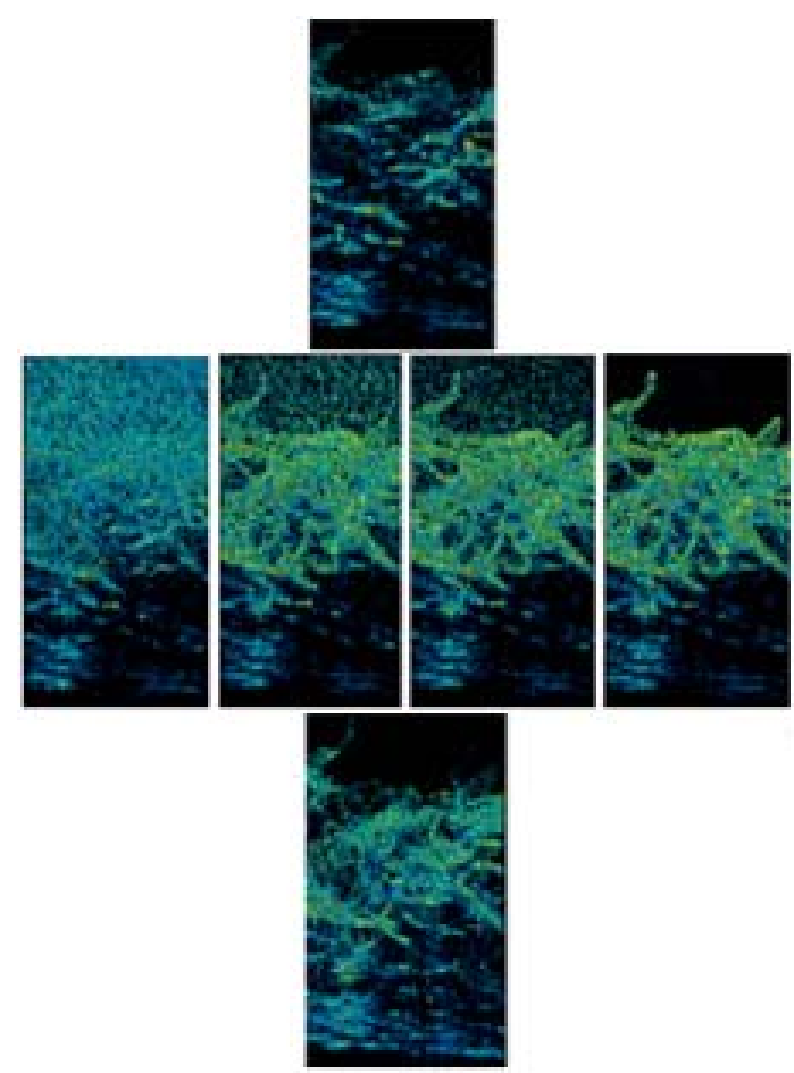

Fig. 2. OCM images of a collagen sponge (side view) incubated with 71.5 $\mathrm{nm}$ diameter gold particles. The images are of a tissue-engineered collagen sponge before (top panel) and 10, 30, 40, and 180 minutes after addition of $71.5 \mathrm{~nm}$ gold particles (central panels, from left to right). The bottom panel is the same imaging volume after extensive rinsing of the sponge with deionized water. Images are $500 \mu \mathrm{m}$ wide. 


\section{Labeling of Cells with Naked Gold Nanoparticles}

Naked $16 \mathrm{~nm}$ and $71.5 \mathrm{~nm}$ gold nanoparticles adhered to methanol-fixed corneal myofibroblasts, staining the cells orange-red and red, respectively (Fig. 3). After 48 hours incubation, $16 \mathrm{~nm}$ nanoparticles appeared, in general, to stain the cells more intensely than $71.5 \mathrm{~nm}$ gold nanoparticles and to stain the cytoplasm more than the cell nuclei, although there was variability in staining intensity and location. From this data, we were led to wonder whether immunogold labeling of stromal cells could be assessed colorimetrically using brightfield microscopy.

\section{Immunogold Labeling of Human Corneal Stromal Cells}

Brightfield microscopy of cells in suspension labeled with $71.5 \mathrm{~nm}$ gold-antibody conjugates revealed intense red staining on part or all of some cell surfaces, whereas control cells displayed no red staining (Fig. 4). The variability of the gold staining may indicate differential antigen expression on different cell phenotypes, inefficient gold labeling, or both. The fraction of red-stained cells was low, and the stained cells were typically morphologically less spherical than stained cells.
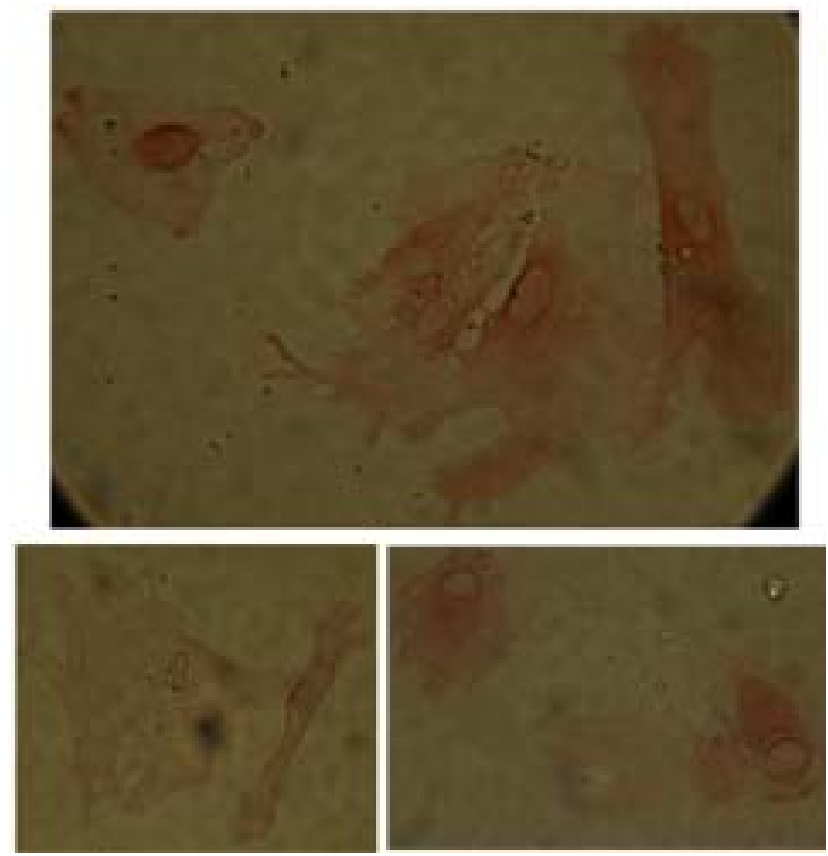

Fig. 3. Unfiltered brightfield images of methanol-fixed corneal myofibroblasts incubated with $16 \mathrm{~nm}$ (top panel) and $71.5 \mathrm{~nm}$ (bottom panels) gold. Total magnification is 400x. In general, nuclei stained less intensely than other cellular material, but there were exceptions (top panel, upper left corner). $71.5 \mathrm{~nm}$ gold-stained cells generally displayed less intense coloration (bottom left panel).

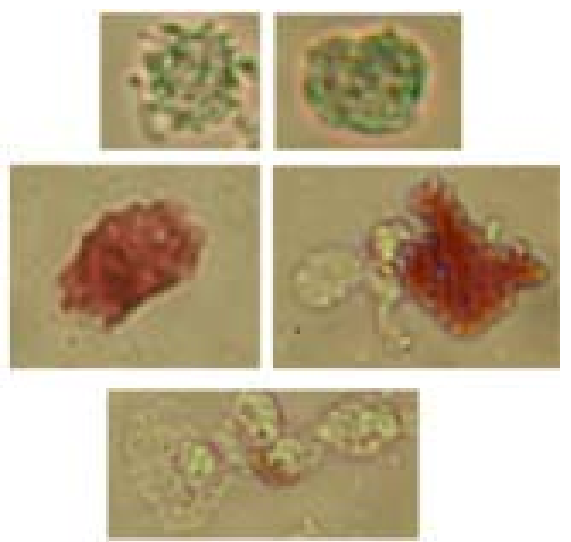

Fig. 4. Unfiltered brightfield images of living corneal stromal cells (top panel) and of cells incubated with primary antibody followed by 71.5 $\mathrm{nm}$ gold-conjugated secondary antibody fragments (central and bottom panels). For the incubations, cell suspensions were in PBS $/ 10 \%$ FBS and were placed on coverslips for imaging.

\section{E. Incubation of cells on collagen sponges with gold conjugates}

Corneal fibroblasts were seeded at high density on collagen sponges and subsequently incubated with the previously mentioned primary antibody and $71.5 \mathrm{~nm}$ goldconjugated secondary antibody fragment. After each incubation, the sponge was washed in PBS and imaged with the OCM (Fig. 5). Cell-seeded sponge images after incubation with the conjugate appeared to have brighter regions than images of the sponge before incubation with the conjugates, although the difference is not large. The post-incubation sponge images had a significantly higher average scattering intensity per sponge voxel (one-tailed two-sample t-test, $\mathrm{n}_{1}=4, \mathrm{n}_{2}=10, \mathrm{p}=0.0007$ ).

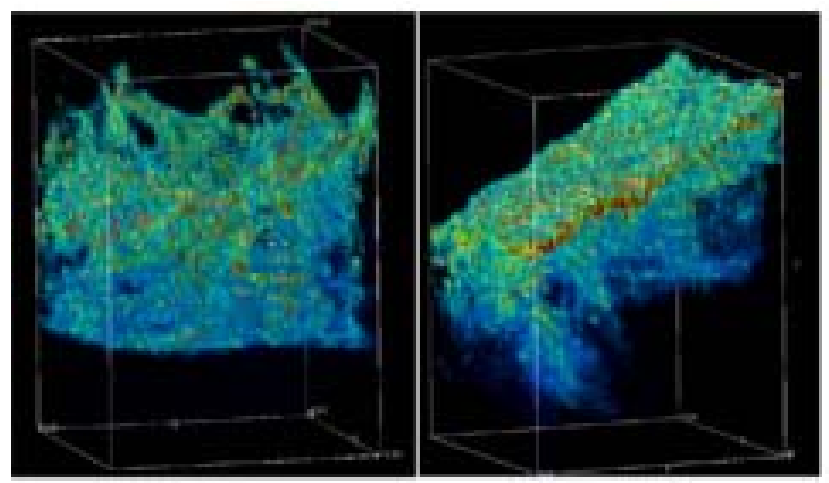

Fig. 5. OCM images of a corneal fibroblast-seeded collagen sponge before incubation with gold conjugate (left panel) and after (right panel). These images were taken after incubating the sponge in primary antibody (left panel) for 12 hours followed by gold conjugate (right panel) for 9 hours. Incubations occurred at $4{ }^{\circ} \mathrm{C}$ with gentle agitation. Images are $500 \mu \mathrm{m} \mathrm{x}$ $500 \mu \mathrm{m}$ wide and $700 \mu \mathrm{m}$ deep. 


\section{Discussion}

Our OCM data shows that larger gold particles in solution scatter more intensely than smaller particles. As gold particles get larger, their conjugation to antibodies becomes more difficult and they increase attenuation of the OCM sample beam. Both factors contribute to an upper size limit for practical use of gold particles as OCM contrast agents.

We have shown that through the use of monodisperse, uniform gold nanoparticles, we can achieve improved contrast of OCM images of tissue-engineered corneal construct. Naked gold particles most likely bind to collagen through noncovalent charge interactions and Van der Waals forces $[6,7]$.

We can also monitor gold nanoparticle binding to corneal stromal cells with a simple brightfield inverted microscope. This method can help correlate OCM data of changes in cellular backscattering properties to immunogold labeling. It should be noted that brightfield microscopy cannot distinguish between antibody-specific and nonspecific gold binding to cells. Since all cells were incubated with gold conjugates in PBS, however, it seems likely that unbound gold would aggregate and thus would not contribute to cellular labeling. In fact, brightfield images revealed several micron-sized aggregates of gold particles in the gold conjugate solution.

Although more data needs to be taken with OCM, brightfield microscopy, and electron microscopy to confirm whether immunogold-labeled cells are contributing to the OCM signal increase of cell-seeded collagen sponges, the results of the current study show that our OCM is sensitive to the addition of gold colloid (both bare and conjugated to antibodies) to a complex tissue sample. Ideally, biological contrast agents should produce clearly visible and striking changes to OCM images of labeled biological tissue. Further experimentation with immunogold labeling is needed to optimize cellular contrast enhancement.

\section{CONCLUSION}

Our data suggest that gold nanoparticles are promising contrast-enhancing agents for engineered tissue and cells imaged with OCM. OCM can detect gold nanoparticles and gold conjugates, both in solution and associated with collagen and cell-seeded engineered tissue. Brightfield microscopy can detect binding of gold particles to cells and cell material. Immunogold labeling of human corneal stromal cells can potentially be used as a method for assessing cell phenotype of living cells in engineered tissue. This would allow monitoring of the way cells respond to physical forces on the tissue, the addition of soluble factors to the media, and other changes in cellular environment. Other cell surface markers can be targeted to label different cell phenotypes. This study provides an initial step towards using OCM to monitor living cells and cellular phenotype in engineered tissue.

\section{ACKNOWLEDGMENT}

We would like to thank Dr. Barbara Hoeling and Dr. Daniel Petersen for their contributions to the OCM, and Sung-Eun Lee and Tonya Icenogle for their contributions to engineered tissue and bioreactor design.

\section{REFERENCES}

[1] M. E. Fini. "Keratocyte and Fibroblast Phenotypes in the Repairing Cornea," Progress in Retinal and Eye Research, vol. 18, pp. 529-551, 1999.

[2] J. V. Jester, P. A. Barry, G. J. Lind, W. M. Petroll, R. Garana, and H. D. Cavanaugh, "Corneal keratocytes: in situ and in vitro organization of cytoskeletal contractile proteins", Invest. Ophthalmol. Vis. Sci., vol. 35(2), pp. 730-43, 1994.

[3] J. V. Jester, T. Moller-Pedersen, J. Huang, C. M. Sax, W. T. Kays, H. D. Cavanaugh, W. M. Petroll, and J. Piatigorsky, "The Cellular Basis for Corneal Transparency: Evidence for 'Corneal Crystallins'," Journal of Cell Science, vol. 112, pp. 613-622, 1999.

[4] S. K. Masur, J. K. Cheung, and S. Antohi. "Identification of integrins in cultured corneal fibroblasts and in isolated keratocytes," Investigative Ophthalmology and Visual Science, vol. 34, pp. 2690-8, 1993.

[5] S. K. Masur, R. J. Conors, Jr, J. K. Cheung, and S. Antohi. 1999. "Matrix adhesion characteristics of corneal myofibroblasts," Investigative Ophthalmology and Visual Science, vol. 40, pp. 904-910, 1999.

[6] J. L. M. Leunissen, and J. R. De Mey, Immuno-Gold Labeling in Cell Biology (Verklij, AJ, and Leunissen, JLM, Eds.), Boca Raton, FL: CRC Press, 1989.

[7] J. Roth, Techniques in Immunochemistry (Bullock, GR, and Petrusz, P, Eds.), Vol. 2, New York, NY: Academic Press, 1983.

[8] K. Sokolov, M. Follen, J. Aaron, I. Pavlova, A. Malpica, R. Lotan, and R. Richards-Kortum, "Real-Time Optical Imaging of Precancer Using Anti-Epidermal Growth Factor Receptor Antibodies Conjugated to Gold Nanoparticles," Cancer Research, vol. 63, pp. 1999-2004, 2003.

[9] F. Frens, "Controlled nucleation for the regulation of the particle size in monodisperse gold suspensions," Nature Physical Science, vol. 241, pp. 20-22, 1973.

[10] E. J. Orwin, and A. Hubel, "In vitro culture characteristics of corneal epithelial, endothelial, and keratocytes in a native collagen matrix," Tissue Engineering, vol. 6(4), pp. 307-319, 2000 . 